\title{
New structural determinants of charged local anaesthetic block of voltage-gated sodium channels
}

\author{
Péter Lukács, René Cervenka, Vaibhavkumar S Gawali, Xaver Koenig, Ágnes K Mike, Lena Rubi, Karlheinz Hilber, \\ Hannes Todt \\ From 18th Scientific Symposium of the Austrian Pharmacological Society (APHAR). Joint meeting with the \\ Croatian, Serbian and Slovenian Pharmacological Societies. \\ Graz, Austria. 20-21 September 2012
}

\section{Background}

Some blockers of voltage-gated $\mathrm{Na}^{+}$and $\mathrm{Ca}^{2+}$ channels are assumed to pass through the membrane and then bind to amino acids in the internal vestibule by access from the internal side of the membrane. However, in the heart isoform of the voltage-gated $\mathrm{Na}^{+}$channel, in L-type calcium channels and in T-type calcium channels an additional external access pathway (EAP) through the protein has been suggested. Furthermore, in voltage-gated $\mathrm{Na}^{+}$channels $\left(\mathrm{Na}_{\mathrm{V}}\right)$ mutations at a specific site in the middle of the domain IV transmembrane segment 6 (site 1575 in $\mathrm{rNa}_{\mathrm{V}} 1.4,1760$ in $\mathrm{rNa}_{\mathrm{V}} 1.4$ ) open an EAP for QX-222, a permanently charged, hydrophilic lidocaine analogue. Recently, the first crystal structure of a $\mathrm{Na}_{V}$ was published [1]. In this bacterial channel structure $\left(\mathrm{Na}_{\mathrm{V}} \mathrm{Ab}\right)$ the side chain homologous to rNa 1.4 I1575 (I202 in $\mathrm{Na}_{V} \mathrm{Ab}$ ) is in close contact with a pore-loop sidechain, homologous to $\mathrm{rNa}_{\mathrm{V}} 1.4 \mathrm{~W} 1531$ (W179 in $\mathrm{Na}_{\mathrm{V}} \mathrm{Ab}$ ). In contrast, in all currently available structural homology models of $\mathrm{Na}_{\mathrm{V}}$, W1531 is not in contact with I1575. If W1531 were positioned as suggested in the $\mathrm{Na}_{\mathrm{V}} \mathrm{Ab}$ structure then a reduction in the length of the side chain at this site would be predicted to open the EAP. To test this hypothesis we generated the mutations W1531A and W1531G and tested these constructs for block by external QX-222.

\section{Methods}

Whole-cell patch clamp measurements were done on TsA 201 cells transiently transfected with plasmids coding the
$\mathrm{rNa}_{\mathrm{V}} 1.4 \alpha$ subunit and its mutants, the sodium channel $\beta 1$ subunit and GFP. Block levels were derived at $2 \mathrm{~Hz}$ stimulation frequency from a holding potential of $-120 \mathrm{mV}$.

\section{Results}

Mutations W1531A and W1531G were found to be sensitive to extracellular QX-222 (block: $20.6 \pm 2 \%$ and $17.7 \pm 3.5 \%$, respectively).

\section{Conclusions}

Our results indicate that position 1531 is an important part of the EAP in $\mathrm{rNa}_{\mathrm{V}} 1.4$, as predicted from the crystal structure of $\mathrm{Na}_{V} \mathrm{Ab}$. Thus the bacterial channel $\mathrm{Na}_{V} \mathrm{Ab}$ appears to share important structural motifs with eukaryotic sodium channels.

\section{Acknowledgements}

This study was funded by the Austrian Science Fund (FWF, grants P210006B11 and W1232-B11).

Published: 17 September 2012

\section{Reference}

1. Payandeh J, Scheuer T, Zheng N, Catterall WA: The crystal structure of a voltage-gated sodium channel. Nature 2011, 475:353-358.

doi:10.1186/2050-6511-13-S1-A70

Cite this article as: Lukács et al:: New structural determinants of

charged local anaesthetic block of voltage-gated sodium channels. BMC

Pharmacology and Toxicology 2012 13(Suppl 1):A70.

\footnotetext{
* Correspondence: hannes.todt@meduniwien.ac.at

Department of Neurophysiology and Neuropharmacology, Center for Physiology and Pharmacology, Medical University of Vienna, 1090 Vienna, Austria
}

(c) 2012 Lukács et al; licensee BioMed Central Ltd. This is an Open Access article distributed under the terms of the Creative Commons 